\title{
Semiaquatic adaptations in a giant predatory dinosaur
}

\section{Nizar Ibrahim, ${ }^{1 *}$ Paul C. Sereno, ${ }^{1}$ Cristiano Dal Sasso, ${ }^{2}$ Simone Maganuco, ${ }^{2}$ Matteo Fabbri, ${ }^{3}$ David M. Martill, ${ }^{4}$ Samir Zouhri, ${ }^{5}$ Nathan Myhrvold, ${ }^{6}$ Dawid A. lurino ${ }^{7}$}

${ }^{1}$ Organismal Biology and Anatomy, University of Chicago, Chicago, IL 60637, USA. ${ }^{2}$ Museo di Storia Naturale di Milano, Corso Venezia 55, 20121 Milan, Italy. ${ }^{3}$ School of Earth Sciences, University of Bristol, Queen's Road, Bristol, BS8 1RJ, UK. ${ }^{4}$ School of Earth and Environmental Sciences, University of Portsmouth, Burnaby Road, Portsmouth, PO1 3QL, UK. ${ }^{5}$ Laboratoire de Géosciences, Faculté des Sciences Aïn Chock, Université Hassan II, Casablanca, Morocco. ${ }^{6}$ Intellectual Ventures, 3150 139th Avenue SE, Bellevue, WA 98005, USA. ${ }^{7}$ Dipartimento di Scienze della Terra, Sapienza Università di Roma, Piazzale Aldo Moro 5, 00185 Rome, Italy.

*Corresponding author. E-mail: nibrahim@uchicago.edu

We describe adaptations for a semiaquatic lifestyle in the dinosaur Spinosaurus aegyptiacus. These adaptations include retraction of the fleshy nostrils to a position near the mid-region of the skull and an elongate neck and trunk that shift the center of body mass anterior to the knee joint. Unlike terrestrial theropods, the pelvic girdle is downsized, the hind limbs are short, and all of the limb bones are solid without an open medullary cavity, for buoyancy control in water. The short, robust femur with hypertrophied flexor attachment and the low, flat-bottomed pedal claws are consistent with aquatic foot-propelled locomotion. Surface striations and bone microstructure suggest that the dorsal "sail" may have been enveloped in skin that functioned primarily for display on land and in water.

Bones of the predatory dinosaur Spinosaurus aegyptiacus first came to light over a century ago from Upper Cretaceous rocks in Egypt (1-3) but were destroyed in WWII (4). More recently, isolated teeth and bones (5) and the anterior half of an adult skull (6) have been discovered in the Kem Kem beds of eastern Morocco (Fig. 1A) and equivalent horizons in Algeria, but are insufficiently complete to estimate the size, proportions, and functional adaptations of this species. Here we report the discovery of a partial skeleton of Spinosaurus aegyptiacus from the middle of the Kem Kem sequence (Fig. 1B), which is likely Cenomanian in age ( 97 Mya) (7).

The subadult skeleton, here designated the neotype of Spinosaurus aegyptiacus (8), preserves portions of the skull, axial column, pelvic girdle, and limbs. It was discovered in fluvial sandstone that has yielded remains of the sauropod Rebbachisaurus (9) and three other medium to large theropods (an abelisaurid, Deltadromeus, Carcharodontosaurus) $(7,10)$. We regard two additional Kem Kem theropods, Sigilmassasaurus brevicollis and Spinosaurus maroccanus $(11,12)$, to be referable to Spinosaurus aegyptiacus (8).

The neotype skeleton and isolated bones referable to Spinosaurus aegyptiacus were scanned with computed tomography, size-adjusted, and combined with a digital recreation of the original Egyptian fossils (Fig. 2A, red). Missing bones were extrapolated between known bones or estimated from other spinosaurids $(6,13,14)$. The digital model of the adult skeleton of Spinosaurus (Fig. 2A), when printed and mounted, measures over $15 \mathrm{~m}$ in length, longer than Tyrannosaurus specimens ( 12.5 m) (15).

A concentrated array of neurovascular foramina open on the anterior end of the snout and appear similar to foramina in crocodilians that house pressure receptors that detect water movement $(8,16)$ (Fig. 2B and fig. S6). The enlarged, procumbent, interlocking anterior teeth are well adapted for snaring fish $(5,6)$ (Fig. $2 \mathrm{~B}$ and fig. S4). The fossa for the fleshy nostril is small and, unlike any other nonavian dinosaur, is retracted to a posterior position to inhibit the intake of water (Fig. 2C and figs. S4 and S6) (8).

Most cervical and dorsal centra are elongate compared to sacral centra, resulting in a proportionately long neck and trunk (Figs. 2A and 3 and tables S1 and S2). The anteriormost dorsal centra, however, are proportionately short, exceptionally broad and concavoconvex (Fig. 2D). These characteristic vertebrae, the affinity of which has been controversial $(7,11,12)$, are referred here to Spinosaurus aegyptiacus based on their association with spinosaurid skeletons in Niger (8) and Egypt (2). The horizontal cervicodorsal hinge created by these broad centra facilitates dorsoventral excursion of the neck and skull in the pursuit of prey underwater. The distal two-thirds of the tail comprises vertebrae with relatively short centra, diminutive zygapophyses and anteroposteriorly compressed neural spines (Fig. 2G). The affinity of these caudal elements has been uncertain (17), but comparisons with associated remains from Egypt (2) and more proximal caudals in the neotype (Fig. 2A) allow referral to Spinosaurus. Short centra and reduced neural arch articulations enhance lateral bending during tail propulsion in bony fish (18).

The forelimb has hypertrophied deltopectoral and olecranon processes for powerful flexion and extension (Fig. 2A). Elongate manual phalanges (Fig. 2H) and less recurved, manual unguals likely referable to Spinosaurus (11) possibly used in gaffing and slicing aquatic prey suggest that the manus is proportionately longer than in earlier spinosaurids $(13,14)$.

The pelvic girdle and hind limb are considerably reduced in Spinosaurus (Fig. 2A). The surface area of the iliac blade is approximately one-half that in most other theropods (table S1), and the supraacetabular crest that supports the hind limb is low (Fig. 2F). Hind limb length is just over $25 \%$ of body length (table S1). In a plot of forelimb, hind limb and body length (Fig. 3), Spinosaurus and other large theropods maintain fairly similar forelimb lengths. Relative hind limb length, however, is noticeably less in the spinosaurid Suchomimus (25\%) and especially in Spinosaurus (19\%) than in other large tetanuran theropods.

Unlike other mid or large-sized dinosaurs, the femur in Spinosaurus is substantially shorter than the tibia (Fig. 2, I and $\mathrm{J}$ and table S1). In smaller-bodied bipedal dinosaurs, short femoral proportions indicate increased stride length and enhanced speed. In Spinosaurus this is clearly not the case, given the short hind limb. The femur in Spinosaurus has an unusually robust attachment for the caudofemoral musculature, which is anchored along nearly one-third of the femoral shaft (Fig. 2I) suggesting powerful posterior flexion of the hind limb. The articulation at the knee joint for vertical limb support, in contrast, is reduced. The distal condyles of the femur are narrow, and the cnemial crest of the tibia is only moderately expanded (Fig. 2I, J). Together these features recall the shortened condition of the femur in early cetaceans $(19,20)$ and in extant semiaquatic mammals that use their hind limbs in foot-propelled paddling (21). 
Pedal digit I is unusually robust and long in Spinosaurus: unlike Allosaurus or Tyrannosaurus the first phalanx of digit I in Spinosaurus is the longest nonungual phalanx in the pes (fig. S1) and would have been in contact with the substrate in stationary pose. The pedal unguals are proportionally large, long, low and flat-bottomed (Fig. 2K and figs. S1 and S2), features that differ markedly from the deeper recurved unguals in other large theropods. The unguals in Spinosaurus are reminiscent of the flattened pedal unguals of shorebirds that do not perch (22). In addition the toes of some shorebirds have fleshy lobes and interdigital webbing that enhance foot-propelled propulsion. The lengthened digit I and flattened pedal unguals in Spinosaurus suggests that the foot may have been adapted to traversing soft substrates or webbed for paddling.

Increase in bone mass and density are common skeletal modifications in terrestrial vertebrates transitioning to a semiaquatic existence (23). In Spinosaurus this was achieved by enlarging midline display structures, eliminating open medullary cavities in the long bones, and increasing bone density. In subadult Spinosaurus the dorsal neural spines are composed primarily of dense bone with only a narrow central zone of cancellous bone (Fig. 4D) and long bones have solid shafts (Fig. 4, A and $\mathrm{C}$ ) with no development of the open medullary cavity that is present in other theropods, including early spinosaurids (Fig. 4B). Bone density within the long bones, in addition, is $30-40 \%$ greater in Spinosaurus than in other theropods (8).

We estimated a center of body mass for a flesh rendering of Spinosaurus created over the digital skeleton (8). Center of mass estimates for several theropods have been expressed as a percentage of femoral length measured anteriorly from the hip joint (24). The center of mass in a biped must be located over the middle one-third of the pes to generate a plausible mid stance pose (25). In our flesh rendering of Spinosaurus, the center of body mass is positioned in front of both hip and knee joints at a distance greater than femur length (fig. S3), suggesting that forelimb support was required during terrestrial locomotion. Spinosaurus appears to have been poorly adapted to bipedal terrestrial locomotion. The forward position of the center of mass within the ribcage may have enhanced balance during foot-propelled locomotion in water.

These adaptations suggest that Spinosaurus was primarily a piscivore, subsisting on sharks, sawfish, coelacanths, lungfish and actinopterygians that were common in the $\operatorname{Kem} \operatorname{Kem}$ river system $(5,7,11)$. A long narrow skull and powerful forelimbs are also present in earlier spinosaurids, which like Spinosaurus (26) have been interpreted as predominantly piscivorous $(13,14,27,28)$.

The locomotor adaptations outlined above, however, mark a profound departure in form and function from early spinosaurids. Prominent among these are the reduced pelvic girdle, short hind limb, short femur, and long, low, flat-bottomed pedal unguals, all of which can be verified in the second partial skeleton described by Stromer as "Spinosaurus B" $(2,8)$. We note here that Spinosaurus must have been an obligate quadruped on land, the first among theropod dinosaurs, given the usual horizontal sacroiliac joint and the anterior location of the estimated center of body mass (8). Baryonyx was interpreted as a facultative quadruped based on its long skull and neck and robust humerus (27), but this was not confirmed by discovery of more complete hind limb remains of the related Suchomimus (13).

In Spinosaurus we infer foot-powered paddling from the relatively short femur with hypertrophied flexor attachment and strong pedal digit I, as occurs in semiaquatic mammals such as early cetaceans (19-21). Low, flat-bottomed pedal unguals are coincident with digital lobes or webbing in shore birds (22), and interdigital webbing has been reported in theropod dinosaurs (29).

Reduction of the pelvic girdle and hind limb and concomitant enhancement of axial-powered locomotion are common among semiaquatic vertebrates. The flexibility of the tail and the form of the neural spines in Spinosaurus suggest tail-assisted swimming. Like extinct and extant semiaquatic reptiles, Spinosaurus used lateral undulation of the tail, in contrast to vertical axial undulation adopted repeatedly by semiaquatic mammals $(20,21)$.

The dorsal "sail" in Spinosaurus, the tallest axial structure documented among dinosaurs, has been argued to be a thermoregulatory surface, a muscle- or fat-lined hump (30), or a display structure. Stromer (1) drew an analogy to the skin-covered neural spines of the crested chameleon, Trioceros cristatus (Fig. 4E). As in T. cristatus, the 'sail' of Spinosaurus is centered over the trunk (Fig. 2A). The shape and positioning of the spine are also similar and the base of the neural spine is expanded anteroposteriorly with edges marked by ligament scars (Fig. 2E). In Trioceros a tendon of multisegmental axial musculature attaches to the expanded base of the neural spine (Fig. 4E). The upper portion of the spine has sharp anterior and posterior edges, is marked by fine vertical striae (Figs. 2E and 4D), and is spaced away from adjacent spines, unlike the broader, contiguous, paddle-shaped dorsal spines of other spinosaurids (13). The striated surface, sharp edges, and dense, poorly vascularized internal bone of the spines suggest that they were wrapped snugly in skin and functioned as a display structure that would have remained visible while swimming.

\section{References and Notes}

1. E. Stromer, Ahb. König. Bayer. Akad. Wissen. Math-Phys. Kl. 28, 1-32 (1915).

2. E. Stromer, Abh. König. Bayer. Akad. Wissen. Math-Naturwissen. Abt. 22, 1 79 (1934).

3. J. B. Smith, M. C. Lamanna, H. Mayr, K. J. Lacovara, New information regarding the holotype of Spinosaurus aegyptiacus stromer, 1915. J. Paleontol. 80, 400-406 (2006). doi:10.1666/00223360(2006)080[0400:NIRTHO]2.0.CO;2

4. W. Nothdurft, J. Smith, The Lost Dinosaurs of Egypt (Random House, NY, 2002).

5. P. Taquet, D. Russell, C. R. Acad. Sci. 299, 347-353 (1998).

6. C. Dal Sasso, S. Maganuco, E. Buffetaut, M. A. Mendez, J. Vert. Paleont. 25, 888-896 (2005). doi:10.1671/0272-4634(2005)025[0888:NIOTSO]2.0.CO;2

7. P. C. Sereno, D. B. Dutheil, M. Iarochene, H. C. E. Larsson, G. H. Lyon, P. M. Magwene, C. A. Sidor, D. J. Varricchio, J. A. Wilson, Predatory dinosaurs from the Sahara and Late Cretaceous faunal differentiation. Science 272, 986991 (1996). Medline doi:10.1126/science.272.5264.986

8. See the supplementary materials on Science Online.

9. R. Lavocat, C. R. Congr, Géol. Int. Paleontol. (1952). Acad. Sci. 1, 65-68 (1954).

10. L. Mahler, Record of Abelisauridae (Dinosauria: Theropoda) from the Cenomanian of Morocco. J. Vert. Paleont. 25, 236-239 (2005). doi:10.1671/0272-4634(2005)025[0236:ROADTF]2.0.CO;2

11. D. A. Russell, Bull. Mus. Nat. d'Hist. Nat. Paris 18, 349-402 (1996)

12. B. McFeeters, M. J. Ryan, S. Hinic-Frlog, C. Schröder-Adams, H. Sues, A reevaluation of Sigilmassasaurus brevicollis (Dinosauria) from the Cretaceous of Morocco. Can. J. Earth Sci. 50, 636-649 (2013). doi:10.1139/cjes-2012$\underline{0129}$

13. P. C. Sereno, A. L. Beck, D. B. Dutheil, B. Gado, H. C. E. Larsson, G. H. Lyon, J. D. Marcot, O. W. M. Rauhut, R. W. Sadleir, C. A. Sidor, D. D. Varricchio, G. P. Wilson, J. A. Wilson, A long-snouted predatory dinosaur from Africa and the evolution of spinosaurids. Science 282, 1298-1302 (1998). Medline doi:10.1126/science.282.5392.1298

14. A. J. Charig, A. C. Milner, Bull. Nat. Hist. Mus 53, 11-70 (1997).

15. C. Brochu, J. Vert. Paleont. Mem. 7, 22 (suppl. 4), 1-138 (2002).

16. D. B. Leitch, K. C. Catania, Structure, innervation and response properties of integumentary sensory organs in crocodilians. J. Exp. Biol. 215, 4217-4230 (2012). Medline doi:10.1242/jeb.076836

17. F. E. Novas, F. Dalla Vecchia, D. F. Pais, Rev. Mus. Argent. Cien. Nat. 7, 167-175 (2005).

18. F. E. Fish, G. V. Lauder, Passive and active flow control by swimming fishes and mammals. Annu. Rev. Fluid Mech. 38, 193-224 (2006). doi:10.1146/annurev.fluid.38.050304.092201

19. S. I. Madar, Adv. Vert. Paleobiol 1, 353-378 (1998).

20. P. D. Gingerich, Land-to-sea transition in early whales: Evolution of Eocene Archaeoceti (Cetacea) in relation to skeletal proportions and locomotion of 
living semiaquatic mammals. Paleobiol 29, 429-454 (2003). doi:10.1666/0094-8373(2003)029<0429:LTIEWE > 2.0.CO;2

21. F. E. Fish, Structure and mechanics of nonpiscine control surfaces. IEEE J. Oceanic Eng. 29, 605-621 (2004). doi:10.1109/JOE.2004.833213

22. A. Manegold, Two additional synapomorphies of grebes Podicipedidae and flamingos Phoenicopteridae. Acta Ornithol. 41, 79-82 (2006). doi:10.3161/068.041.0113

23. E. Amson, C. de Muizon, M. Laurin, C. Argot, V. de Buffrénil, Gradual adaptation of bone structure to aquatic lifestyle in extinct sloths from Peru. Proc. Biol. Sci. 281, 20140192 (2014). Medline doi:10.1098/rspb.2014.0192

24. K. T. Bates, R. B. J. Benson, P. L. Falkingham, A computational analysis of locomotor anatomy and body mass evolution in Allosauroidea (Dinosauria: Theropoda). Paleobiol 38, 486-507 (2012). doi:10.1666/10004.1

25. S. M. Gatesy, M. Bäker, J. R. Hutchinson, Paleobiol 29, 535-544 (2009).

26. E. Stromer, Abh. König. Bayer. Akad. Wissen., Math.-Naturwissen. Abt. 33, 1-102 (1936).

27. A. J. Charig, A. C. Milner, Baryonyx, a remarkable new theropod dinosaur. Nature 324, 359-361 (1986). Medline doi:10.1038/324359a0

28. E. J. Rayfield, A. C. Milner, V. B. Xuan, P. G. Young, Functional morphology of spinosaur 'crocodile-mimic' dinosaurs. J. Vert. Paleont. 27, 892-901 (2007). doi:10.1671/0272-4634(2007)27[892:FMOSCD]2.0.CO;2

29. M. L. Casanovas et al., Zub. Monogr. 5, 135-163 (1993).

30. J. B. Bailey, J. Paleontol. 71, 1124-1146 (1997).

31. P. Cignoli, M. Corsini, G. Ranzuglia, Meshlab: An open-source 3d mesh processing system. Ercim news 73, 45-46.

32. M. D. Abràmoff, P. J. Magalhães, S. J. Ram, Image processing with ImageJ. Biophot. Internat. 11, 36-43 (2004).

33. A. H. Lee, Histological organization and its relationship to function in the femur of Alligator mississippiensis. J. Anat. 204, 197-207 (2004). Medline doi:10.1111/j.0021-8782.2004.00275.x

34. A. S. Quemeneur, V. Buffrénil, M. Laurin, Microanatomy of the amniote femur and inference of lifestyle in limbed vertebrates. Biol. J. Linn. Soc. Lond. 3, 644-655 (2013). doi:10.1111/bij.12066

35. E. Bourdon, J. Castanet, A. de Ricqlès, P. Scofield, A. Tennyson, H. Lamrous, J. Cubo, Bone growth marks reveal protracted growth in New Zealand kiwi (Aves, Apterygidae). Biol. Lett. 5, 639-642 (2009). Medline doi:10.1098/rsbl.2009.0310

36. A. H. Lee, P. M. O’Connor, Bone histology confirms determinate growth and small body size in the noasaurid theropod Masiakasaurus knopfleri. J. Vert. Paleont 4, 865-876 (2013). doi:10.1080/02724634.2013.743898

37. D. C. Evans et al., Osteology and bone microstructure of new, small theropod dinosaur material from the early Late Cretaceous of Morocco. DOI: 10.1016/j.gr.2014.03.01648.

38. P. J. Bybee, A. H. Lee, E.-T. Lamm, Sizing the Jurassic theropod dinosaur Allosaurus: Assessing growth strategy and evolution of ontogenetic scaling of limbs. J. Morphol. 267, 347-359 (2006). Medline doi:10.1002/jmor.10406

39. J. R. Horner, K. Padian, Age and growth dynamics of Tyrannosaurus rex. Proc. Biol. Sci. 271, 1875-1880 (2004). Medline doi:10.1098/rspb.2004.2829

40. D. J. Varricchio, J. R. Moore, G. M. Erickson, M. A. Norell, F. D. Jackson, J. J. Borkowski, Avian paternal care had dinosaur origin. Science 322, 18261828 (2008). Medline doi:10.1126/science.1163245

41. A. J. de Ricqlès, K. Padian, J. R. Horner, E.-T. Lamm, N. Myhrvold, Osteohistology of Confuciusornis sanctus (Theropoda: Aves). J. Vertebr. Paleontol. 23, 373-386 (2003). doi:10.1671/02724634(2003)023[0373:OOCSTA]2.0.CO;2

42. P. C. Sereno, F. E. Novas, The skull and neck of the basal theropod Herrerasaurus ischigualastensis. J. Vert. Paleontol. 13, 451-476 (1993). doi:10.1080/02724634.1994.10011525

43. R. N. Martínez, P. C. Sereno, O. A. Alcober, C. E. Colombi, P. R. Renne, I. P. Montañez, B. S. Currie, A basal dinosaur from the dawn of the dinosaur era in southwestern Pangaea. Science 331, 206-210 (2011). Medline doi:10.1126/science.1198467

44. D. Soares, Neurology: An ancient sensory organ in crocodilians. Nature 417, 241-242 (2002). Medline doi:10.1038/417241a

45. D. Foffa, A. R. Cuff, J. Sassoon, E. J. Rayfield, M. N. Mavrogordato, M. J. Benton, Functional anatomy and feeding biomechanics of a giant Upper Jurassic pliosaur (Reptilia: Sauropterygia) from Weymouth Bay, Dorset, UK. J. Anat. 225, 209-219 (2014). Medline doi:10.1111/joa.12200

46. J. A. Wilson, P. C. Sereno, Early evolution and higher-level phylogeny of sauropod dinosaurs. J. Vert. Paleont. Mem. 7, 1-68 (1998).

47. L. M. Witmer, Nostril position in dinosaurs and other vertebrates and its significance for nasal function. Science 293, 850-853 (2001). Medline doi:10.1126/science.1062681

48. R. Amiot, E. Buffetaut, C. Lecuyer, X. Wang, L. Boudad, Z. Ding, F. Fourel, S. Hutt, F. Martineau, M. A. Medeiros, J. Mo, L. Simon, V. Suteethorn, S. Sweetman, H. Tong, F. Zhang, Z. Zhou, Oxygen isotope evidence for semiaquatic habits among spinosaurid theropods. Geology 38, 139-142 (2010). doi:10.1130/G30402.1

\section{ACKNOWLEDGMENTS}

We thank C. Abraczinskas for final drafts of all text figures; M. Auditore for discussions and drawings; T. Keillor, L. Conroy, and E. Fitzgerald for image processing and modeling; R. Masek, T. Keillor, E. Fitzgerald, and F. Bacchia for fossil preparation; C. Straus, N. Gruszauskas, D. Klein, and the University of Chicago Medical Center for computed tomographic scanning; M. Zilioli, F. Marchesini, M. Pacini, and P. Vignola for preparation of histological samples; A. Di Marzio (Siemens Milano) and P. Biondetti (Fondazione Ospedale Maggiore IRCCS, Milan) for CT scanning and rendering of MSNM V4047; and the Island Fund of the New York Community Trust and National Geographic Society (grant SP-13-12) for support of this research. We also thank the embassy of the Kingdom of Morocco in Washington, DC, for their continued interest in this project. Skeletal measurements and geologic data are included in the SM. The neotype is going to be deposited at the Faculté des Sciences Aïn Chock (University of Casablanca), Casablanca, Morocco.

\section{Supplementary Materials}

www.sciencemag.org/cgi/content/full/science.1258750/DC1

Supplementary Text

Figs. S1 to S8

Tables $\mathrm{S} 1$ to S5

References (31-48)

15 July 2014; accepted 3 September 2014

Published online 11 September 2014; 10.1126/science.1258750 


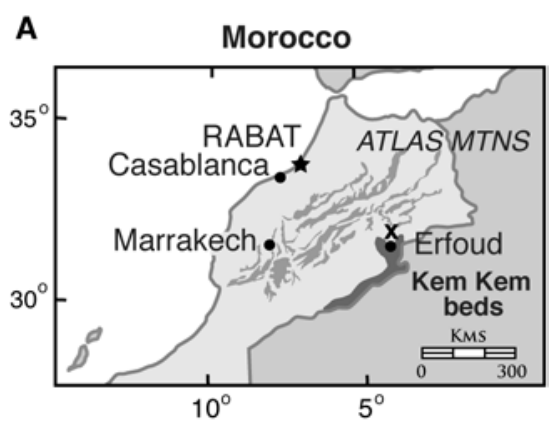

B

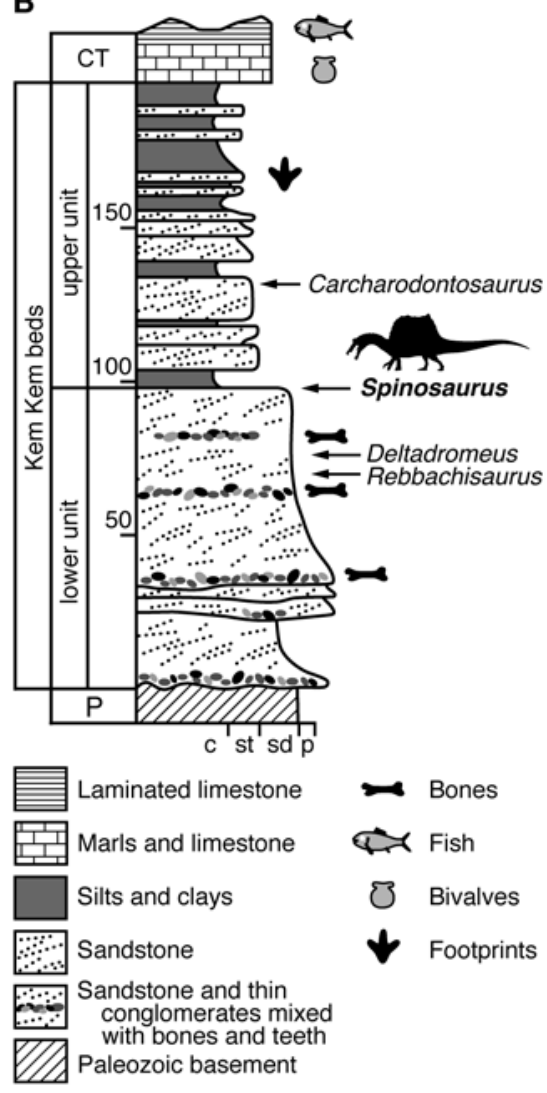

Fig. 1. Geographic location and stratigraphic position of the neotype skeleton of Spinosaurus aegyptiacus. (A) Locality (X) situated $18 \mathrm{~km}$ northeast of Erfoud in southeastern Morocco. (B) Stratigraphic position at the base of the upper unit of the Kem Kem beds with correlative positions of associated remains of contemporary dinosaurs. Abbreviations: c, clay; $\mathrm{CT}$, Cenomanian-Turonian limestone; $\mathrm{p}$, pebbles; $\mathrm{P}$, Paleozoic; sd, sandstone; st, siltstone. 


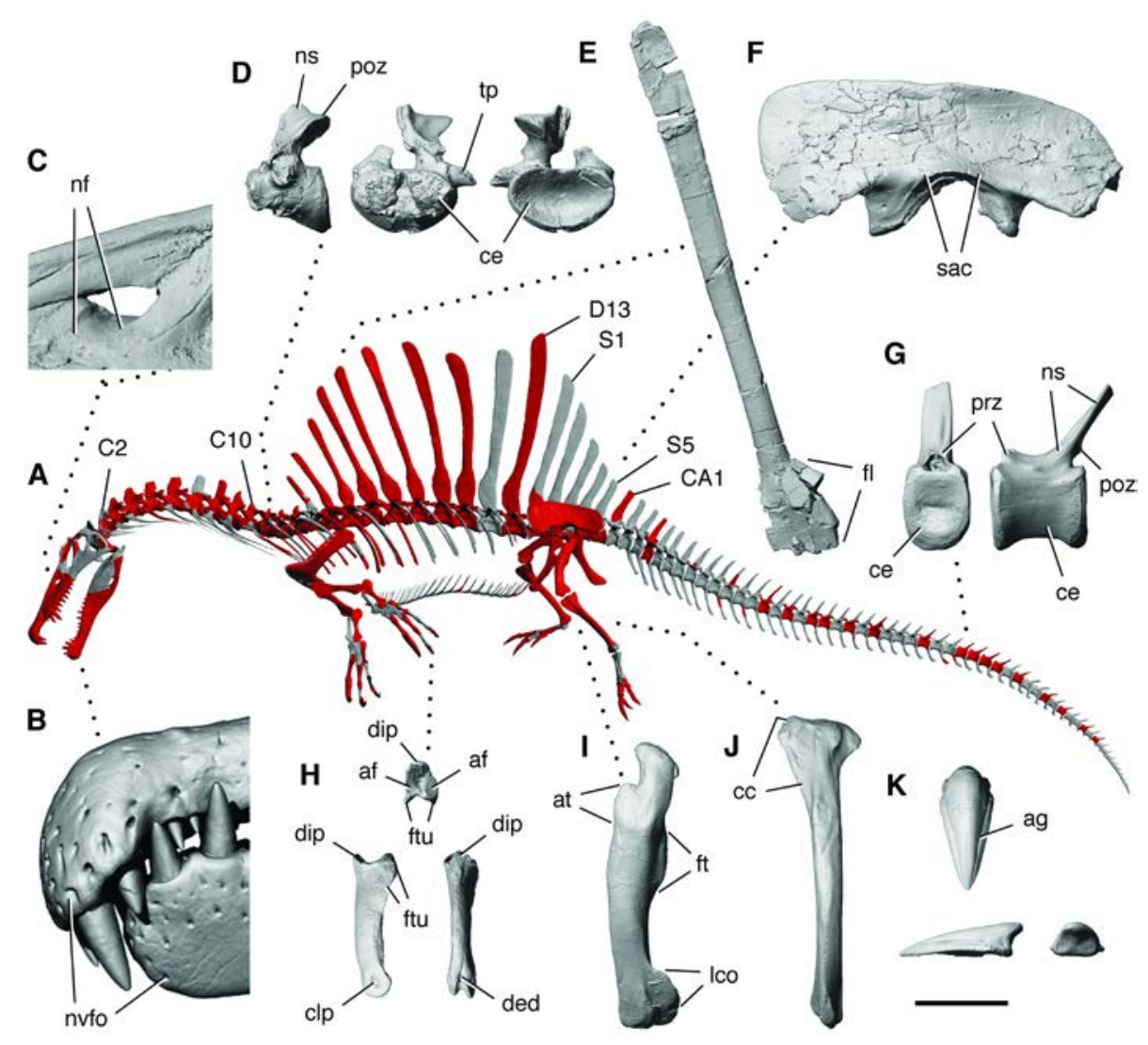

Fig. 2. Semiaquatic skeletal adaptations in Spinosaurus aegyptiacus. (A) Skeletal reconstruction in swimming pose showing known bones (red) based on size-adjusted, computed tomographic scans of the neotype (FSAC-KK 11888), referred specimens, and drawings of original bones (1). (B) Rostral neurovascular foramina in lateral view (MSNM V4047 and a digital restoration of the holotypic lower jaw). (C) Narial fossa in lateral view (MSNM V4047). (D) Anterior dorsal vertebra ( D1) in lateral, anterior and posterior views (UCRC PV601). (E) Dorsal neural spine (D8) in left lateral view (FSAC-KK 11888). (F) Left ilium in lateral view (FSAC-KK 11888). (G) Mid caudal vertebra ( CA30, reversed) in anterior and left lateral views (UCRC PV5). (H) Right manual II-1 phalanx in proximal, lateral and dorsal views (FSAC-KK 11888). (I) Left femur in lateral view (FSAC-KK 11888). (J) Right tibia (reversed) in lateral view (FSAC-KK 11888). (K) Right pedal digit III ungual in dorsal, lateral and proximal views (FSAC-KK 11888). Abbreviations: af, articular facet; ag, attachment groove; at, anterior trochanter; C2, 10, cervical vertebra 2, 10; CA1, caudal vertebra 1; cc, cnemial crest; ce, centrum; clp, collateral ligament pit; D13, dorsal vertebra 13; ded, dorsal extensor depression; dip, dorsal intercondylar process; fl, flange; ft, fourth trochanter; ftu, flexor tubercle; Ico, lateral condyle; nf, narial fossa; ns, neural spine; nvfo, neurovascular foramina; poz, postzygapophysis; prz, prezygapophysis; S1, 5, sacral vertebra 1, 5; sac, supraacetabular crest; tp, transverse process. Institutional abbreviations: FSAC, Faculté des Sciences Aïn Chock, Casablanca; MSNM, Museo di Storia Naturale di Milano; UCRC, University of Chicago Research Collection, Chicago. Scale bars equal $10 \mathrm{~cm}$ in (B) to $(D),(G),(H)$, and $(K)$, and $20 \mathrm{~cm}$ in $(E),(F),(I)$, and $(J)$. 

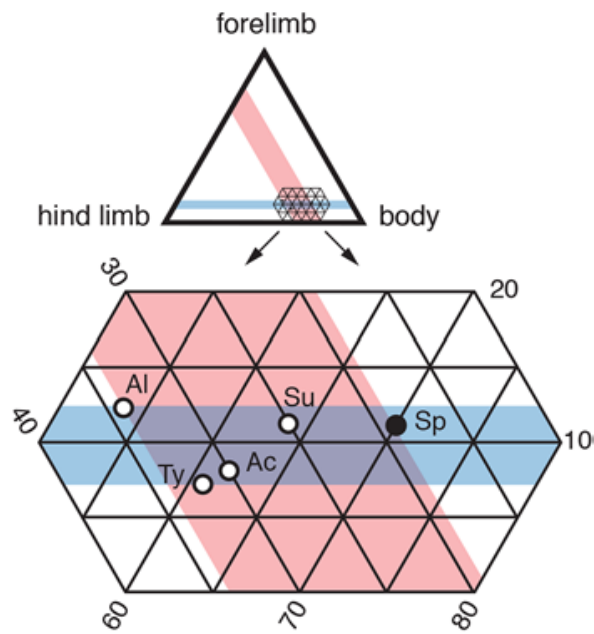

Fig. 3. Ternary morphospace plot comparing forelimb, hind limb and body length. Forelimb (humerus + radius + metacarpal II), hind limb (femur + tibia + metatarsal III), and body length (snout tip to posterior extremity of pelvic girdle) are plotted as percentages of the sum of forelimb, hind limb and body lengths in Spinosaurus aegyptiacus and other large tetanuran theropods (data from Table 1). Blue zone shows range of forelimb length, from $7 \%$ (Tyrannosaurus) to $12 \%$ (Allosaurus). Hind limb length (red zone) ranges from 34\% (Allosaurus) to $19 \%$ (Spinosaurus). Abbreviations: Ac, Acrocanthosaurus; Al, Allosaurus; Sp, Spinosaurus; Su, Suchomimus; Ty, Tyrannosaurus.
Fig. 4. Bone microstructure and dorsal spine form. (A) Mid-shaft thin section of the right femur of Spinosaurus aegyptiacus (FSAC-KK 11888). (B) Mid-shaft thin section of the right femur of Suchomimus tenerensis (MNN GAD608). (C) Cross-sectional view of right manual II-1 phalanx of Spinosaurus aegyptiacus (FSAC-KK 11888). (D) Thin section of a dorsal neural spine (distal section) in Spinosaurus aegyptiacus (FSAC-KK 11888). (E) Dorsal vertebrae with tall neural spines and spinal tendons in a cleared and stained specimen of Trioceros (Chamaeleo) cristatus (FMNH 19886). Abbreviations: cb, cancellous bone; ec, erosional cavities; Hb, Haversian bone; mc, medullary cavity; ns, neural spine; pb, primary bone; sc, scapula; st, striae; te, tendon of multi-segment spinal muscle. Institutional abbreviations: FMNH, Field Museum of Natural History. Scale bars equal $2 \mathrm{~cm}$ in (A) and (C), $3 \mathrm{~cm}$ in $B, 5 \mathrm{~mm}$ in (D), and $1 \mathrm{~cm}$ in (E).

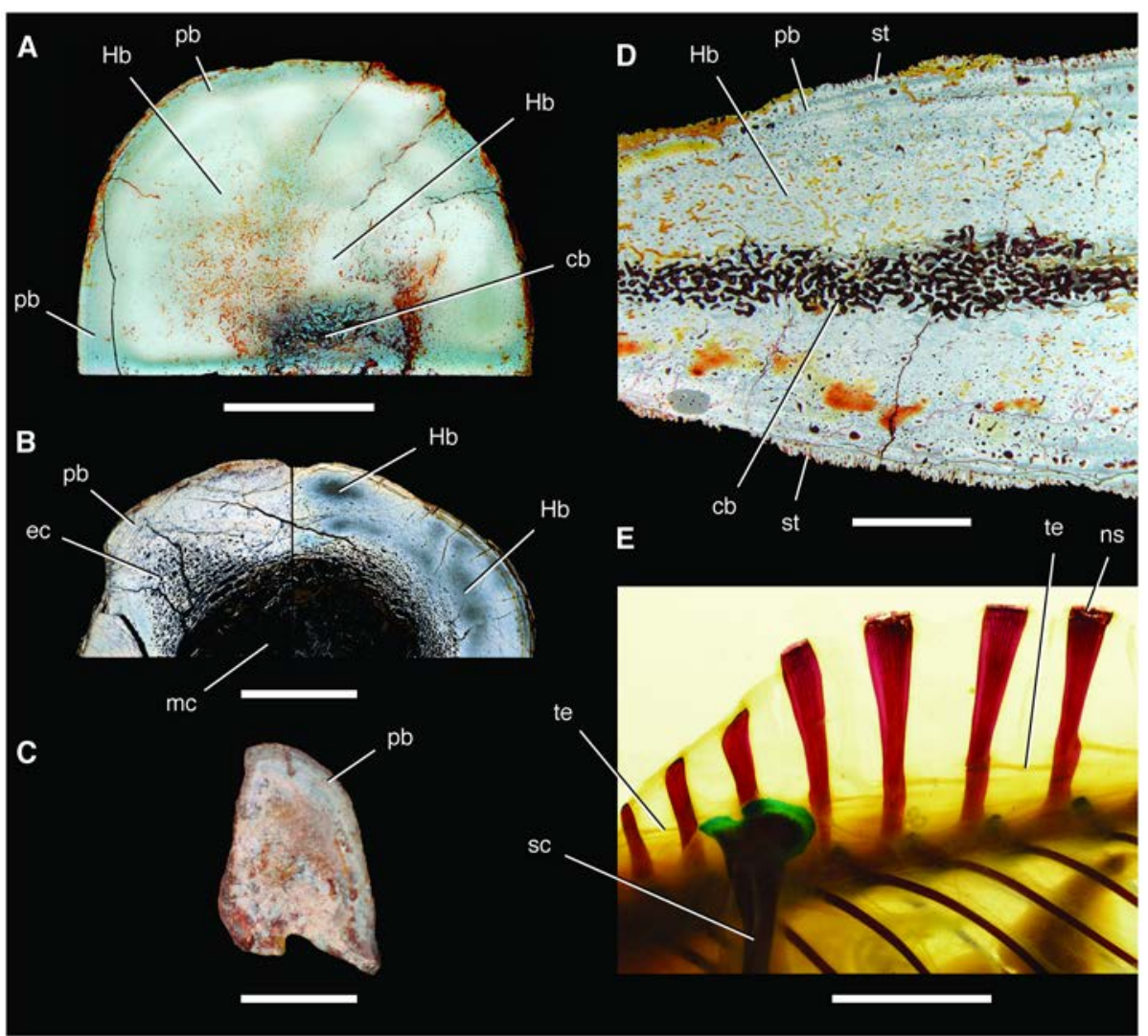

